\title{
Transient Stability Enhancement of Wind Farms Connected to a Multi-machine Power System by Using an Adaptive ANN-controlled SMES
}

\author{
${ }^{1}$ S.M. Muyeen, ${ }^{2}$ Hany M. Hasanien, and ${ }^{1}$ Ahmed Al-Durra \\ ${ }^{1}$ Department of Electrical Engineering, The Petroleum Institute, Abu Dhabi 2533, United Arab \\ Emirates \\ ${ }^{2}$ Electrical Power and Machines Department, Faculty of Engineering, Ain Shams University, \\ Cairo, 11517, Egypt (e-mail:Hanyhasanien@ieee.org)
}

Abstract-This paper presents a novel adaptive artificial neural network (ANN)-controlled superconducting magnetic energy storage (SMES) system to enhance the transient stability of wind farms connected to a multi-machine power system during network disturbances. The control strategy of SMES depends mainly on a sinusoidal pulse width modulation (PWM) voltage source converter (VSC) and an adaptive ANN-controlled DC-DC converter using insulated gate bipolar transistors (IGBT). The effectiveness of the proposed adaptive ANN-controlled SMES is then compared with that of proportional-integral (PI)-controlled SMES optimized by response surface methodology and genetic algorithm (RSM-GA) considering both of symmetrical and unsymmetrical faults. For realistic responses, real wind speed data and two-mass drive train model of wind turbine generator system is considered in the analyses. The validity of the proposed system is verified by the simulation results which are performed using the laboratory standard dynamic power system simulator PSCAD/EMTDC. Notably, the proposed adaptive ANN-controlled SMES enhances the transient stability of wind farms connected to a multi-machine power system.

Index Terms-DC-DC converter, superconducting magnetic energy storage (SMES) system, transient stability, voltage source converter (VSC), wind energy. 


\section{INTRODUCTION}

$\mathrm{A}^{\mathrm{S}}$ a result of exhaustion of the fossil fuel in generating electrical power from conventional power plants, the increase in oil price, and the major interest in obtaining a clean environment, many efforts have been done to produce electrical energy from the renewable energy sources such as photovoltaic systems and wind energy conversion systems. The wind energy is becoming one of the mainstream power sources in many countries around the world. According to Global Wind Energy Council (GWEC) statistics, global wind power installations increased by $35.8 \mathrm{GW}$ in 2010, bringing the total installed wind energy capacity up to $194.4 \mathrm{GW}$, a $22.5 \%$ increase on the $158.7 \mathrm{GW}$ installed at the end of 2009 [1]. It is expected that the wind energy will contribute to the world electricity by $12 \%$ in 2020 [2]. Due to the huge installations of wind turbines to the existing networks, many problems should be addressed, studied, and analyzed such as transient stability improvement of wind farms connected to multi-machine power systems.

Currently, there are several types of energy storage devices in the market such as battery energy storage systems (BESS), energy capacitor systems (ECS), flywheel energy storage systems (FESS), and superconducting magnetic energy storage (SMES) systems. Although, the BESS are the most commonly used in the industry, they have limited lifetime and voltage and current limitations. FESS involves another rotating machinery which is not preferable and standby loss is high. Charging method of ECS and controlling scheme is not that easy for ECS. Because of the recent development of power electronics, superconductivity, and computer science, the SMES system has received a great attention in the power systems applications. It has been utilized in distributed energy storage, spinning reserve, load following, automatic generation control, power quality improvement, reactive power flow control, voltage control, and transient stability enhancement [3]. SMES has several merits include high storage efficiency which may reach $90 \%$ or higher. Moreover, it has a very fast response, where it can convert the power in the range of megawatts in several milliseconds [4]. Also, the number of charging and discharging cycles of SMES is not limited. However, the main demerit of the SMES system is its high cost, but it is expected to decrease in the near future with the development of power electronics, control strategies, and continuous research. Recently, the researches have been started to evaluate the SMES cost for electric power compensation [5].

SMES is a large superconducting coil that can store electric energy in the magnetic field produced by the flow of a dc current through it. This coil is maintained at a specified low temperature by a cryogenic or 
dewar that contains helium or nitrogen liquid vessels. The real power and reactive power can be charged in or delivered from the coil of SMES according to the power system requirements. The interface between the power system and SMES coil is the power conditioning system (PCS) which has a very important role to demonstrate the validity of SMES in the dynamic control of the power system [3].

Several studies have been done to improve the stability of electric power systems with SMES. The dynamics and stability of wind and diesel turbine generators with SMES unit has been presented in an isolated power system [6]. Moreover, a combination of a rotating exciter and a SMES has been done for efficient power system stabilization [7]. In [8], an adaptive nonlinear excitation and SMES controller has been proposed to augment the transient stability of a single synchronous generator connected to an infinite bus power system but a simplified power system model was used. Furthermore, transient stability has been enhanced for an industrial cogeneration system with SMES unit [9]. The performance of a large turbine generator unit connected to a high voltage direct current system has been improved with the SMES unit [10]. In addition, a fuzzy logic-controlled SMES has been presented to improve the transient stability of a grid-connected synchronous generator system [11]. Furthermore, the coordination effect of a fuzzy logiccontrolled SMES and optimal reclosing on the transient stability in a multi-machine power system during unsuccessful reclosing of circuit breakers has been investigated. Although the fuzzy logic systems incorporate an alternative way of thinking, it depends mainly on the experience of the designer in tuning the membership functions.

There are several literature surveys related to the applications of SMES to improve the transient stability of wind generator systems [12], [13]. In these reported works, the fuzzy logic system and PI controller were used to control the SMES unit. Although, the PI controller is the most commonly used in the industry due to its robustness and it offers a wide stability margin, it suffers from the sensitivity to the parameter variations and nonlinearity of dynamic systems. Notably, till now, the application of different control strategies to SMES is not enough. The control technologies can provide a much efficient SMES unit which in turn leads to improve the transient stability of the wind generator systems.

In this study, an adaptive artificial neural network (ANN)-controlled SMES is presented for enhancing the transient stability of fixed-speed wind farms connected to a multi-machine power system. The control scheme of SMES depends on a sinusoidal pulse width modulation (PWM) voltage source converter (VSC) 
and DC-DC converter using insulated gate bipolar transistors (IGBT). An adaptive ANN controller is introduced as the control methodology of DC-DC converter. For realistic responses, real wind speed data are used in this study. Two-mass drive train model of wind turbine generator system is used in the analyses as it has great influence on the fault analysis. To the best of our knowledge, the proposed controller has not so far been reported in power system literature for improving the transient stability of wind farms connected to a multi-machine power system. The effectiveness of the proposed adaptive ANN-controlled SMES is then compared with that of an optimally tuned proportional-integral (PI)-controlled SMES by the response surface methodology and genetic algorithm (RSM-GA) considering both of symmetrical and unsymmetrical faults. This is another salient feature of this study because earlier proposed intelligent controllers [12] for SMES have not been compared with optimally tuned conventional controllers and therefore, the comparison is not well acceptable. The validity of the proposed system is verified by the simulation results which are performed using the laboratory standard dynamic power system simulator PSCAD/EMTDC. From the simulation results, it can be concluded that the proposed adaptive ANNcontrolled SMES can enhance the transient stability of wind farms connected to a multi-machine power system.

\section{Model System}

\section{A. Model System under Study}

The system under study consists of a 9-bus main power system connected with two wind farms, as shown in Fig. 1. Synchronous generators 1 and 2 (SG1 and SG2) are steam turbine and hydro turbine generators, respectively. The IEEE generic turbine model and approximate mechanical-hydraulic speed governing system [14] is used for SG1. The IEEE "non-elastic water column without a surge tank" turbine model and "PID control including pilot and servo dynamics" speed-governing system [15] is used for SG2. IEEE alternator supplied rectifier excitation system (AC1A) [16] is used in the exciter model of SG1 and SG2. The Wind farms WF1 and WF2 are connected to the main system through a long and short transmission lines, respectively. Induction generators (IGs) are used as wind generators in both wind farms. The rated capacity of each wind farm is 50 MVA. Each wind farm consists of five fixed-speed wind generators of 10 MVA power rating. The aggregated wind farm model is considered herein where several 
small size wind generators can be lumped to obtain a 10 MVA wind generator [17]. A capacitor bank (C) is used for reactive power compensation of $\mathrm{IG}$ at steady state and its value is chosen so that the power factor of the wind power station during the rated operation becomes unity [18]. The parameters of generators are shown in Table I. The system base is 100 MVA.

\section{B. Wind Turbine Modeling}

The mathematical relation of mechanical power extraction from the wind can be expressed as follows [19]-[21]:

$$
P_{w}=0.5 \rho \pi R^{2} V_{w}^{3} C_{P}(\lambda, \beta)
$$

where $P_{w}$ is the extracted power from the wind, $\rho$ is the air density $\left[\mathrm{kg} / \mathrm{m}^{3}\right], R$ is the blade radius $[\mathrm{m}], V_{w}$ is the wind speed $[\mathrm{m} / \mathrm{s}]$, and $C_{p}$ is the power coefficient which is a function of tip speed ratio, $\lambda$, and blade pitch angle, $\beta$ [deg.]. The turbine characteristics used are shown in Fig. 2 [22]. The two-mass drive train parameters of wind generators are shown in Table $\mathrm{I}$, where $\mathrm{H}_{\mathrm{g}}$ and $\mathrm{H}_{\mathrm{wt}}$ are the generator and wind turbine inertia constants, respectively, and $\mathrm{K}_{\mathrm{w}}$ is the shaft stiffness between the two masses.

In this study, the conventional pitch controller is used. The purpose of using the pitch controller is to maintain the output power of wind generator at the rated level by controlling the blade pitch angle of turbine blade when the wind speed is over the rated speed.

\section{Modeling of SMES}

The model of SMES unit used in this study, shown in Fig. 3, consists of a six-pulse PWM VSC using IGBTs, a DC-link capacitor of $60 \mathrm{mF}$, a DC-DC converter, a superconducting coil of inductance $0.24 \mathrm{H}$, and a three-phase transformer $(66 \mathrm{kV} / 0.77 \mathrm{kV})$ with 0.2 p.u leakage reactance.

The stored energy, $E$ [Joule], in a SMES system and its rated power, $P$ [Watt], are described by the following equations:

$$
\begin{gathered}
E=\frac{1}{2} L_{s m} I_{s m}^{2} \\
P=\frac{d E}{d t}=L_{s m} I_{s m} \frac{d I_{s m}}{d t}=V_{s m} I_{s m}
\end{gathered}
$$

where $L_{s m}$ is the inductance of the superconducting coil, $I_{s m}$ is the DC current flowing through the coil, and $V_{s m}$ is the instantaneous voltage across the coil. The rated values of $E$ and $P$ of a SMES system under study 
are $0.05 \mathrm{MWH}$ and $50 \mathrm{MW}$, respectively. In this work, the SMES coil is initially charged by a $1 \mathrm{kV}$ external DC source with ramp up time few seconds. The SMES unit is equipped with voltage source converter (VSC) and DC-DC converter. The DC-DC converter controls the real power exchange with the power system and the VSC controls the reactive power.

\section{1) PWM VSC}

The VSC is a three-phase rectifier/inverter that connects the superconducting coil with the AC power system through the impedance of the coupling transformer. The well-known cascaded control scheme is considered in this study, as shown in Fig. 4. The dq quantities and three-phase electrical quantities are related to each other by the reference frame transformation. The angle of the transformation is detected from three-phase voltages $\left(\mathrm{v}_{\mathrm{a}}, \mathrm{v}_{\mathrm{b}}, \mathrm{v}_{\mathrm{c}}\right)$ at the high voltage side of the transformer using Phase-Locked Loop (PLL) system. The main target of VSC is the control of wind farm terminal voltage and DC-link voltage. In light of vector control, the difference between the reference DC-link voltage $\mathrm{V}_{\mathrm{dc}}{ }^{*}$ and the actual DC-link voltage $\mathrm{V}_{\mathrm{dc}}$ is the DC-link voltage error, which is the input of the PI-1 controller to produce the reference signal $\mathrm{I}_{\mathrm{d}}{ }^{*}$. In addition, the difference between the reference wind farm terminal voltage $\mathrm{V}_{\mathrm{k}}{ }^{*}$ and its actual value $\mathrm{V}_{\mathrm{k}}$ represents the wind farm terminal voltage error, which is the input of the PI-3 controller to produce the reference signal $\mathrm{I}_{\mathrm{q}}{ }^{*}$. Moreover, both of the difference between $\mathrm{I}_{\mathrm{d}}$ and $\mathrm{I}_{\mathrm{d}}{ }^{*}$, and $\mathrm{I}_{\mathrm{q}}$ and $\mathrm{I}_{\mathrm{q}}{ }^{*}$, follows PI-2 and PI-4 to obtain the reference signals $\mathrm{V}_{\mathrm{q}}{ }^{*}$ and $\mathrm{V}_{\mathrm{d}}{ }^{*}$, respectively. These signals are converted to a three-phase sinusoidal reference waveform $\mathrm{V}_{\mathrm{a}, \mathrm{b}, \mathrm{c}}{ }^{*}$, which is compared with a triangular carrier waveform for generating the gate signals of IGBTs. The chosen frequency of the triangular carrier waveform is 1050 Hz. Fine tuning of the PI controllers' parameters is performed by trial and error method, which is the most commonly used method to achieve the best system performance. The $\mathrm{V}_{\mathrm{dc}}$ is kept constant at $1 \mathrm{kV}$ through the simulation using the PWM VSC. The snubber circuit resistance and capacitance values of the IGBT devices are $5000 \Omega$ and $0.05 \mu \mathrm{F}$, respectively. An over voltage protection system (OVPS) is considered in the simulation for the safety of the VSC unit and the capacitor. The braking chopper is modeled in the DClink in order to protect the DC-link capacitor during the fault situation. The chopper is activated when the DC-link voltage increases over the predefined limit (20\% of the rated value) and dissipates the active power into the resistance during the voltage dip in the grid. 


\section{2) DC-DC Converter}

The energy of superconducting coil is stored or delivered by controlling the DC voltage across the coil using a DC-DC converter, as shown in Fig. 3. The line power $\mathrm{P}_{\mathrm{L}}$ is defined as the power from the wind farm connection (bus 11 or bus 18, as shown in Fig. 1). Bus 11 and 18 are the point of common coupling (PCC) buses. If $\mathrm{P}_{\mathrm{L}}$ is less than the reference power, $\mathrm{P}_{\mathrm{L}-\mathrm{ref}}$, the SMES unit will deliver power to the $\mathrm{AC}$ power system and the converter in this case works in discharging mode and vice versa. Reference power, $\mathrm{P}_{\mathrm{L}-\mathrm{ref}}$, can be a constant value or can be generated using a low pass filter considering line power as its input. In this work, $\mathrm{P}_{\mathrm{L} \text {-ref }}$ is considered as a constant value as power smoothing of wind farm is not focused. The power error signal which is the difference between $\mathrm{P}_{\mathrm{L}}$ and the reference power $\mathrm{P}_{\mathrm{L}-\mathrm{ref}}$, is proceeding to PI-5 controller for producing the duty cycle signal of the DC-DC converter, as shown in Fig. 5. Then the duty cycle signal is compared with the saw tooth carrier wave to generate the gate signals for the converter. In the case of $50 \%$ duty cycle, SMES remains at idle or normal operating condition and in such case a bypass switch across the SMES coil shown in Fig. 3 is closed to avoid depletion of the stored energy. The bypass switch is open for any other value of duty cycle [23], [24]. The chosen frequency of the carrier signal is 100 Hz. In this study, the PI-5 controller is optimally designed by RSM-GA method for obtaining a fair comparison with the proposed adaptive ANN controller.

\section{OPTIMIZATION OF PI CONTROLler by RSM-GA}

There is no doubt that the PI controller is the most commonly used controller in industrial applications because of its robustness and its ability to provide a wide stability margin. However, the PI controllers suffer from the sensitivity of parameters variation and nonlinearity of the dynamic systems. In large electric power system, it is difficult to express the system behavior by a transfer function or mathematical model. Therefore, fine tuning of the PI controllers in these systems is cumbersome and usually done by trial and error method. So, it is important to seek an optimal PI controller to serve these applications. In this study, RSM-GA method is used to optimally design a PI controller.

1) $R S M$

The RSM is a good statistical tool utilized to build a mathematical model by finding the relationship between the design variables and response through statistical fitting method [25]-[27]. Recently, in our 
previous study, the RSM has been used for modeling and analyzing the design of controller parameters used in wind energy conversion system [20].

In this study, the system analysis on the laboratory standard power system simulation package PSCAD/EMTDC [28] is used as numerical simulations to provide the response. The maximum percentage undershoot (MPUS), maximum percentage overshoot (MPOS), and the settling time (Ts) of the wind farm terminal voltage profile are considering the responses. Those are changed by the design variables variant. The second order model of the RSM is used in this study for obtaining more accurate response [20].

2) $G A$

GA is a heuristic powerful search technique used to solve many optimization problems of electric power systems. This technique depends mainly on the concept of survival of the fittest [29], [30]. In this study, GA is used to minimize the MPUS of the voltage $\left(Y_{l}\right)$. The Rank fitness scaling is applied to avoid premature convergence. The process is carried out using the uniform selection technique, which exhibits no bias and minimal spread.

\section{3) Optimization Procedure}

The optimum design procedure is described as follows:

Step 1- Selection of Variables and Levels:

In this study, the proportional gain and integral gain of a PI-5 controller, shown in Fig. 5, are selected to be the design variables. $\mathrm{X}_{1}$ is the proportional gain and $\mathrm{X}_{2}$ is the integral gain. These variables have three levels. Level 1 represents the minimum value of the design variable, level 2 is the average value and level 3 is the maximum value of the design variable [26]. Table II shows the design variables and levels.

\section{Step 2- Design of Simulations:}

The range of design variables and simulation frequency is established by using the central composite design (CCD) as shown in Table III. In this analysis, the experiment frequency of the CCD algorithm is set to 13 [31].

\section{Step 3- PSCAD Program Calculation:}

The PSCAD program calculation is carried out for each experiment and the values of MPUS, MPOS, and $\mathrm{T}_{\mathrm{s}}$ of the voltage profile are stored in a look up Table as given here in Table III. 
The aim of design optimization is to minimize the MPUS $\left(Y_{1}\right)$ with constraints of MPOS $\left(Y_{2}\right)$, and $\mathrm{T}_{\mathrm{s}}$ $\left(Y_{3}\right)$. The three fitted second order polynomial functions are found as follows [20]:

$$
\begin{aligned}
Y_{1}= & 53.47-4.43 x_{1}+3.33 x_{2}-1.47 x_{1} x_{2}+1.33 x_{1}^{2} \\
& -0.86 x_{2}^{2} \\
Y_{2}= & 14.52-0.13 x_{1}-1.74 x_{2}-0.6 x_{1} x_{2}+9.17 x_{1}^{2} \\
& -7.64 x_{2}^{2} \\
Y_{3}= & 1.33-0.05 x_{1}+0.07 x_{2}-0.06 x_{1} x_{2}+0.008 x_{1}^{2} \\
& -0.05 x_{2}^{2}
\end{aligned}
$$

\section{Step 5- GA Optimization:}

GA works on this model and MATLAB optimization Toolbox is considered [32]. The constraints of the optimized problem are described as follows:

- Design variables range is $0.2 \leq X_{1} \leq 1$, and $0.05 \leq X_{2} \leq 0.5$.

- $\quad$ The MPOS constraint $Y_{2} \leq 10 \%$, and $\mathrm{T}_{\mathrm{s}}$ constraint $Y_{3} \leq 3 \mathrm{~s}$.

Table IV shows the GA characteristics. After the $5^{\text {th }}$ iteration, GA optimization was terminated. Table V shows the optimal level and size value of $X_{1}$ and $X_{2}$. At these optimal values, the MPUS equals $49.3 \%$, the MPOS is $8.9 \%$, and $\mathrm{T}_{\mathrm{s}}$ is $1.3 \mathrm{~s}$.

\section{Proposed Adaptive ANN Controller}

The problems of conventional PI controllers can be overcome by using ANN-based control technique. The design of ANN controller does not require the mathematical model of the system under study. Furthermore, it leads to enhance performance, when tuned properly. Also, it requires less tuning effort than the conventional controllers [33]-[35].

1) Description of Adaptive ANN

The adaptive ANN controller has three inputs which are $\mathrm{P}_{\mathrm{L}}, \mathrm{P}_{\mathrm{L}-\mathrm{ref}}$, and the previous output signal of adaptive ANN controller $\mathrm{U}(\mathrm{t}-1)$. Care should be taken into consideration in the choice of the controller inputs, where it affects the system stability. The selection of number of hidden layers and the number of neurons in each hidden layer is performed by trial and error, which is the most commonly used method in ANN architecture design. A three layer feedforward neural structure with three neurons in one hidden layer 
is found to be a good balance between estimation error and ANN complexity. An ANN structure with a $3 \times$ $3 \times 1$ structure (three neurons in input layer, three neurons in the hidden layer, and one neuron in output layer) is shown in Fig. 6. The output of a single neuron can be represented by the following equation:

$$
a_{i}=f_{i}\left(\sum_{j=1}^{n} w_{i j} x_{j}(t)+b_{i}\right)
$$

where $f_{i}$ is the activation function, $w_{i j}$ is the weighting factor, $x_{j}$ is the input signal, and $b_{i}$ is the bias. The activation function used is the tansigmoid function in both the hidden and output layers.

\section{2) Learning Algorithm}

Adaptive ANN controller depends on the Widrow-Hoff adaptation algorithm which is used to adapt the Adaline's weight vector [36]-[38]. The weight update equation is expressed as follows:

$$
W(t+1)=W(t)+\alpha \frac{e_{p}(t) \cdot x(t)}{|x(t)|^{2}}
$$

where $W(t+1)$ is the next value of the weight vector, $W(t)$ is the present value of the weight vector, and $x(t)$ is the present input vector. The weights change results in a change in the error:

$$
\Delta e_{p}(t)=\Delta\left(P_{L-r e f}-P_{L}\right)=-x^{T}(t) \Delta W(t)
$$

From Eq. (8), the weight change is as follows:

$$
\Delta W(t)=W(t+1)-W(t)=\alpha \frac{e_{p}(t) \cdot x(t)}{|x(t)|^{2}}
$$

Merging the last two equations yields:

$$
\Delta e_{p}(t)=-\alpha \frac{e_{p}(t) \cdot x^{T}(t) \cdot x(t)}{|x(t)|^{2}}=-\alpha \cdot e_{p}(t)
$$

It can be noticed that the error is decreased by a factor of $\alpha$ as the weights are changed while holding the input pattern fixed. Presenting a new input pattern starts the next adaptation cycle. The next error is then reduced by a factor of $\alpha$, and the process continues. The initial weight vector is usually chosen to be zero and is adapted until convergence. The choice of $\alpha$ controls the stability and speed of convergence. In this study, $\alpha$ is selected to be 1 for a better error correction.

The proposed algorithm is used to adapt all the weighting factors in the ANN structure. The output signal of adaptive ANN controller $\mathrm{U}(\mathrm{t})$ after being rescaled is used to generate the duty cycle according to the following equation: 


$$
D_{\text {new }}=D_{\text {old }}+k \cdot u
$$

where $D_{\text {old }}$ is the one step time delayed duty cycle signal, and k is a constant.

\section{Simulation Results}

The detailed model of the system under study is considered here to obtain a realistic response. The time domain simulation has been done using PSCAD/EMTDC. The time step and simulation time are chosen $0.00001 \mathrm{~s}$ and $5 \mathrm{~s}$, respectively. As a result of US recent wind farm grid codes, wind farm terminal voltage must return to $90 \%$ of the rated voltage within $3 \mathrm{~s}$ after the start of the voltage drop, otherwise, the wind farm power station has to be shutdown [39]. In this study, US grid codes are used for complying the simulation results. An adaptive ANN-controlled SMES is used to overcome the voltage dip of the wind farm during a network disturbance in a multi-machine power system. The proposed scheme can control the real and reactive power exchange between the SMES unit and Ac power system during a network disturbance. Two-mass drive train model of wind turbine generator system is considered as it has a great influence to the system dynamics.

For the transient stability study, the severe symmetrical three-line to ground fault (3LG) is considered as a network disturbance. The fault occurs at $0.1 \mathrm{~s}$ at fault point F1, as shown in Fig. 1. The circuit breakers (CBs) on the faulted lines are opened at $0.2 \mathrm{~s}$, and finally at $1 \mathrm{~s}$, the CBs are closed. Figs. 7 (a) and (b) show the voltage response at PCCs (bus 18 and bus 11), respectively. Without using SMES, the voltage drop takes place at PCC (bus 18). It causes a sudden increase in the induction generator speed. As a result, the induction generators accelerate and become unstable. In contrast when SMES is used, the required reactive power is supplied from the VSC of SMES unit properly according to the error signals, the voltage at the PCCs can be returned back to the pre-fault level. In addition, DC-DC converter of SMES unit helps to control the real power flow during the disturbance. It can be realized that the voltage response at the PCCs when an adaptive ANN-controlled SMES is used, is a better damped response than that obtained when a PI-controlled SMES optimized by RSM-GA is considered, where the time domain specifications such as maximum percentage undershoot and settling time are reduced in the case of ANN-controlled SMES in comparison with PI-controlled SMES case. The voltage response at the PCCs fully agrees with the US grid codes [39]. Moreover, adaptive ANN-controlled SMES provides less tuning effort and a great time to be 
saved than that of optimized PI-controlled SMES, especially when the system is large and detailed switching model of the VSC is considered with SMES. The turbine and generator rotor speeds for WFIG-6 and WFIG-1 are shown in Figs. 7 (c), (d), and (e), (f), respectively. Notably, the maximum percentage overshoot of these responses is lower when adaptive ANN-controlled SMES is used than that of PIcontrolled SMES. As WFIG-1 is far from the fault point, the generator rotor and turbine speeds become stable with and without SMES. Fig. 7 (g) shows the voltage response at bus-8. It can be seen that adaptive ANN-controlled SMES maintains the voltage constant after the network disturbance with a better damped response. The real power of SMES-2 is shown in Fig. 7 (h). The load angle responses of SG1 and SG2 are illustrated in Figs. 7 (i) and (j), respectively. It can be noted that the transient stability of synchronous generators is enhanced with an adaptive ANN-controlled SMES than that of a PI-controlled SMES. Figs. 7 (k) and (l) show the stored energy of SMES-2 and the DC-link voltage, respectively.

For further verification of the proposed controller, the transient analysis is carried out considering unsymmetrical faults such as single-line to ground fault (1LG), double-line-to-ground fault (2LG) (phase B, C \& ground), and double-line fault (2LL) (between phase B \& C) as a network disturbance. Figs. 8 (a)-(c) show the voltage response at PCC (bus 18) for all these faults. It can be noticed that the voltage response with the proposed adaptive ANN-controlled SMES is faster, lower oscillations, and better damped response in comparison with the response of PI-controlled SMES. From the simulation results, it is clear that the proposed adaptive ANN-controlled SMES can enhance the transient stability of wind farm connected to a multi-machine power system during both symmetrical and unsymmetrical faults.

\section{Conclusion}

In this paper, the transient stability augmentation of wind farms connected to a multi-machine power system has been investigated by using SMES. The SMES real and reactive power flows are controlled by a sinusoidal PWM-based voltage source converter and DC-DC converter. A new control method for SMES power flow control was proposed based on an adaptive ANN controller. The proposed control scheme is compared with an optimally conventional PI controller based control scheme. The optimal method to the conventional PI controller was also performed before comparing the transient performance with the 
proposed ANN controller. The optimum PI controller parameters were determined by the RSM-GA method, which can even be applied to non-linear controllers used in other power system applications.

Finally, it has been concluded that the adaptive ANN controller gives a better transient performance than that of the PI controller for SMES power flow control used in grid-connected wind farms.

\section{REFERENCES}

[1] S.M.Muyeen (Ed.), Wind Energy Conversion Systems: Technology and Trends, Springer, Verlag, UK, ISBN 978-1-4471-22005, February 2012.

[2] The European Wind Energy Association, EWEA Publications, 2005, "Wind Force 12- A Blueprint to Achieve $12 \%$ of the World's Electricity From Wind power by 2020," 2005, [Online], http://www.ewea.org/

[3] Marcelo Gustavo Molina, and Pedro Enrique Mercado, "Power flow stabilization and control of microgrid with wind generation by superconducting magnetic energy storage," IEEE Transactions on Power Electronics, vol. 26, no. 3, pp. 910-922, March 2011.

[4] IEEE Task Force on Benchmark Models for Digital Simulation of FACTS and Custom-Power Controllers, T\&D Committee, "Detailed modeling of superconducting magnetic energy storage (SMES) system," IEEE Transactions on Power Delivery, vol. 21, no. 2, pp. 699-710, April 2006.

[5] Shinichi Nomura, Takakazu Shintomi, Shirabe Akita, Tanzo Nitta, Ryuichi Shimada, and Shinichiro Meguro, "Technical and cost evaluation on SMES for electric power compensation," IEEE Transactions on Applied Superconductivity, vol. 20, no. 3, pp. 1373-1378, June 2010.

[6] S.C. Tripathy, M. Kalantar, and R. Balasubramanian, "Dynamics and stability of wind and diesel turbine generators with superconducting magnetic energy storage unit on an isolated power system," IEEE Transactions on Energy Conversion, vol. 6, no. 4, pp. 579-585, December 1991.

[7] Y. Mitani, and K. Tsuji, "Power system stabilization by superconducting magnetic energy storage connected to rotating exciter," IEEE Transactions on Applied Superconductivity, vol. 3, no. 1, pp. 219-222, March 1993.

[8] Yoke Lin Tan, and Youyi Wang, "Augmentation of transient stability using a superconducting coil and adaptive nonlinear control," IEEE Transactions on Power Systems, vol. 13, no. 2, pp. 361-366, May 1998.

[9] Cheng-Ting Hsu, "Enhancement of transient stability of an industrial cogeneration system with superconducting magnetic energy storage unit," IEEE Transactions on Energy Conversion, vol. 17, no. 4, pp. 445-452, December 2002.

[10] A. Abu-Siada, and Syed Islam, "Application of SMES unit in improving the performance of an AC/DC power system," IEEE Transactions on Sustainable Energy, vol. 2, no. 2, pp. 109-121, April 2011.

[11] Mohd. Hasan Ali, T. Murata, and J. Tamura, "A fuzzy logic-controlled superconducting magnetic energy storage for transient stability augmentation,” IEEE Transactions on Control Systems Technology, vol. 15, no. 1, pp. 144-150, January 2007.

[12] Mohd. Hasan Ali, Minwon Park, In-Keun Yu, Toshiaki Murata, and Junji Tamura, "Improvement of wind generator stability by fuzzy logic-controlled SMES," IEEE Transactions on Industry Applications, vol. 45, no. 3, pp. 1045-1051, May/June 2009.

[13] Li Wang, Shiang-Shong Chen, Wei-Jen Lee, and Zhe Chen, "Dynamic stability enhancement and power flow control of a hybrid wind and marine-current farm using SMES," IEEE Transactions on Energy Conversion, vol. 24, no. 3, pp. 626-639, September 2009.

[14] Working Group on Prime Mover and Energy Supply Models for System Dynamic Performance Studies, "Dynamic models for fossil fuelled steam units on power system studies," IEEE Transactions on Power Systems, vol. 6, no. 2, pp. 753-761, 1991.

[15] Working Group on Prime Mover and Energy Supply Models for System Dynamic Performance Studies, "Hydraulic turbine and turbine control models for system dynamic studies," IEEE Transactions on Power Systems, vol. 7, no. 12, pp. 167-179, 1992.

[16] IEEE Recommended Practice for Excitation System Models for Power System Stability Studies, IEEE Std. 421.5-1992.

[17] D.J. Trudnowski, A. Gentile, J.M. Khan, and E.M. Petritz, "Fixed-speed wind-generator and wind-park modeling for transient stability studies," IEEE Transactions on Power Systems, vol. 19, no. 4, pp. 1911-1917, 2004.

[18] S. M. Muyeen, Mohammad Abdul Mannan, Mohd. Hasan Ali, Rion Takahashi, Toshiaki Murata, and Junji Tamura, "Stabilization of wind turbine generator system by STATCOM," IEEJ Transactions P.E., vol. 126-B, no. 10, pp. 1073-1082, 2006.

[19] S. Heier, "Grid Integration of Wind Energy Conversion System," Chicester, U.K., John Wiley \& Sons Ltd., 1998.

[20] Hany M. Hasanien, and S. M. Muyeen, "Design optimization of controller parameters used in variable speed wind energy conversion system by genetic algorithms", IEEE Transactions on Sustainable Energy, vol. 3, no. 2, pp. 200-208, April 2012.

[21] Hany M. Hasanien, and Essam. A. Al-Ammar, "Dynamic response improvement of doubly fed induction generator based wind farm using fuzzy logic controller", Journal of Electrical Engineering, Slovakia, vol. 63, no. 5, pp. 281-288, September 2012.

[22] S.M. Muyeen, Mohd. Hasan Ali, R. Takahashi, T. Murata, J. Tamura, Y. Tomaki, A. Sakahara, and E. Sasano, "Transient stability analysis of grid connected wind turbine generator system considering multi-mass shaft modeling," Electric Power Components \& Systems, vol. 34, no. 10, pp. 1121-1138, 2006.

[23] I. D. Hassan, R. M. Bucci, and K. T. Swe, "400 MW SMES power conditioning system development and simulation," IEEE Transactions on Power Electronics, vol. 8, no. 3, pp. 237-249, July 1993.

[24] Yunus A. M. S., Masoum M. A. S., and Abu-Siada A., "Application of SMES to enhance the dynamic performance of DFIG during voltage sag and swell," IEEE Transactions on Applied Superconductivity, vol. 22, no. 4, pp. 5702009, 2012. 
[25] Hany M. Hasanien, Ahmed S. Abd-Rabou, and Sohier. M. Sakr, "Design optimization of transverse flux linear motor for weight reduction and performance improvement using response surface methodology and genetic algorithms," IEEE Transactions on Energy Conversion, vol. 25, no. 3, pp. 598-605, September 2010.

[26] Hany M. Hasanien, "Particle swarm design optimization of transverse flux linear motor for weight reduction and improvement of thrust force," IEEE Transactions on Industrial Electronics, vol. 58, no. 9, pp. 4048-4056, September 2011.

[27] Hany M. Hasanien, and S. M. Muyeen, "A Taguchi approach for optimum design of proportional-integral controllers in cascaded control scheme", IEEE Transactions on Power Systems, vol. 28, no. 2, pp. 1636-1644, May 2013.

[28] PSCAD/EMTDC Manual, Manitoba HVDC Research Center, 1994.

[29] Goldbert, D. E., "Genetic algorithm in search, optimization and machine learning," (Addison Wesley 1989).

[30] Hany M. Hasanien, "Design optimization of PID controller in automatic voltage regulator system using Taguchi combined genetic algorithm method", accepted for inclusion in a future issue of IEEE Systems Journal.

[31] Paul Mathews, "Design of experiments with MINITAB," American society of Quality, Quality press, Milwaukee, 2005.

[32] Release 2010 b, "MATLAB Optimization Toolbox," The Math Works press, August 2010.

[33] G. Jahedi, and M.M. Ardehali, "Wavelet based artificial neural network applied for energy enhancement of decoupled HVAC systm”, Energy Conversion and Management, vol. 54, no. 1, pp. 47-56, February 2012.

[34] Ali N. Celik, and Tariq Muneer, "Neural network baed method for conversion of solar radiation data", Energy Conversion and Management, vol. 67, pp. 117-124, March 2013.

[35] S.A. Pourmousavi Kani, and M.M. Ardehali, "Very short-term wind speed prediction: a new artificial neural network-Markov chain model", Energy Conversion and Management, vol. 52, no. 1, pp. 738-745, January 2011.

[36] Hany M. Hasanien, "FPGA implementation of adaptive ANN controller for speed regulation of permanent magnet stepper motor drives," Energy Conversion and Management, vol. 52, issue 2, pp. 1252-1257, Feb. 2011.

[37] Hany M. Hasanien, and S. M. Muyeen, "Speed control of grid-connected switched reluctance generator driven by variable speed wind turbine using adaptive neural network controller", Electric Power Systems Research, vol. 84, no. 1, pp. 206-213, March 2012.

[38] S.M. Muyeen, Hany M. Hasanien, and J. Tamura, "Reduction of frequency fluctuation for wind farm connected power systems by an adaptive artificial neural network controlled energy capacitor system", IET Renewable Power Generation, vol. 6, no. 4, pp. 226-235, July 2012.

[39] Federal Energy Regulatory Commission (FERC), United States of America, Docket No. RM05-4-000 - Order No. 661, "Interconnection for Wind Energy," Issued June 2, 2005.
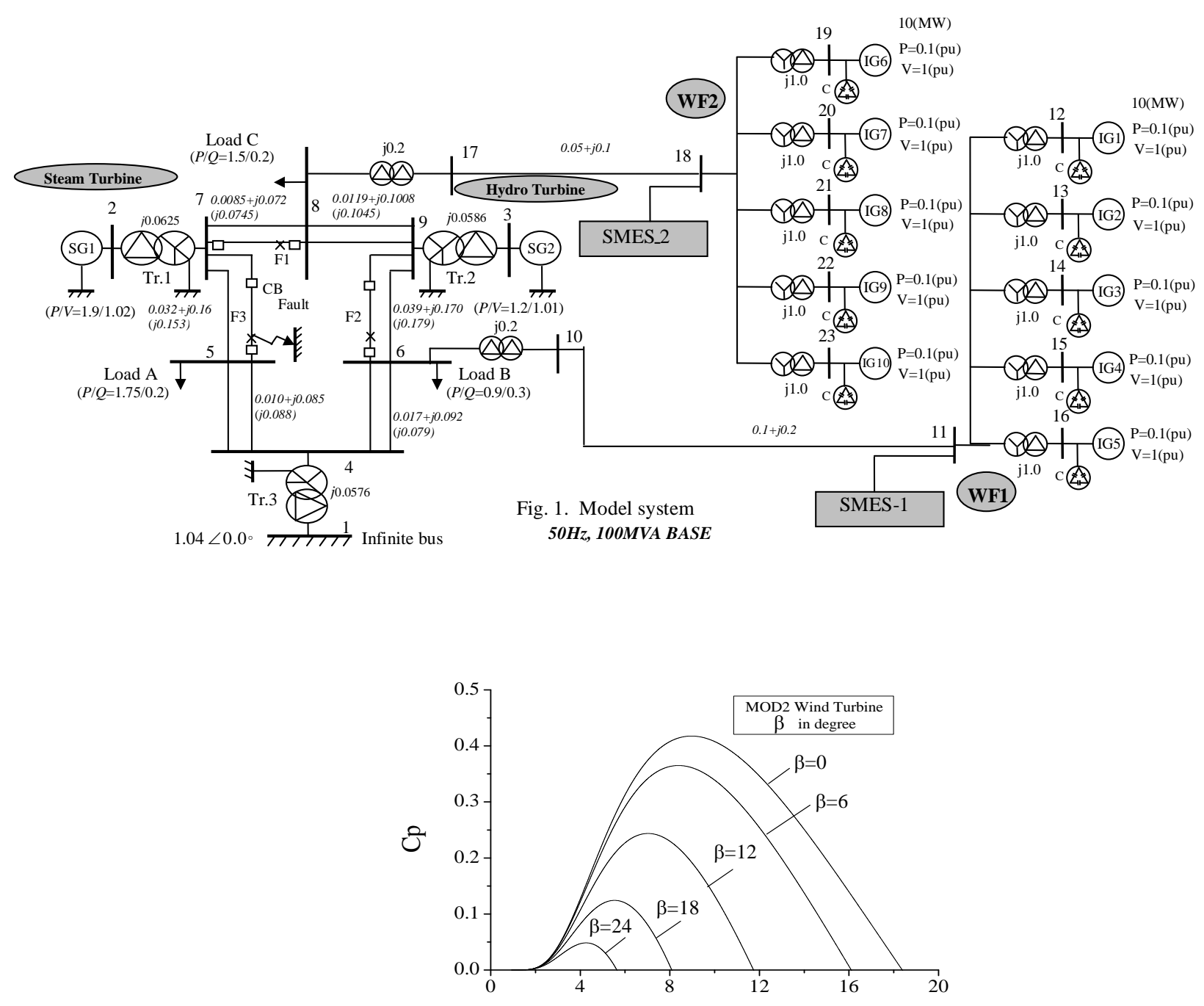


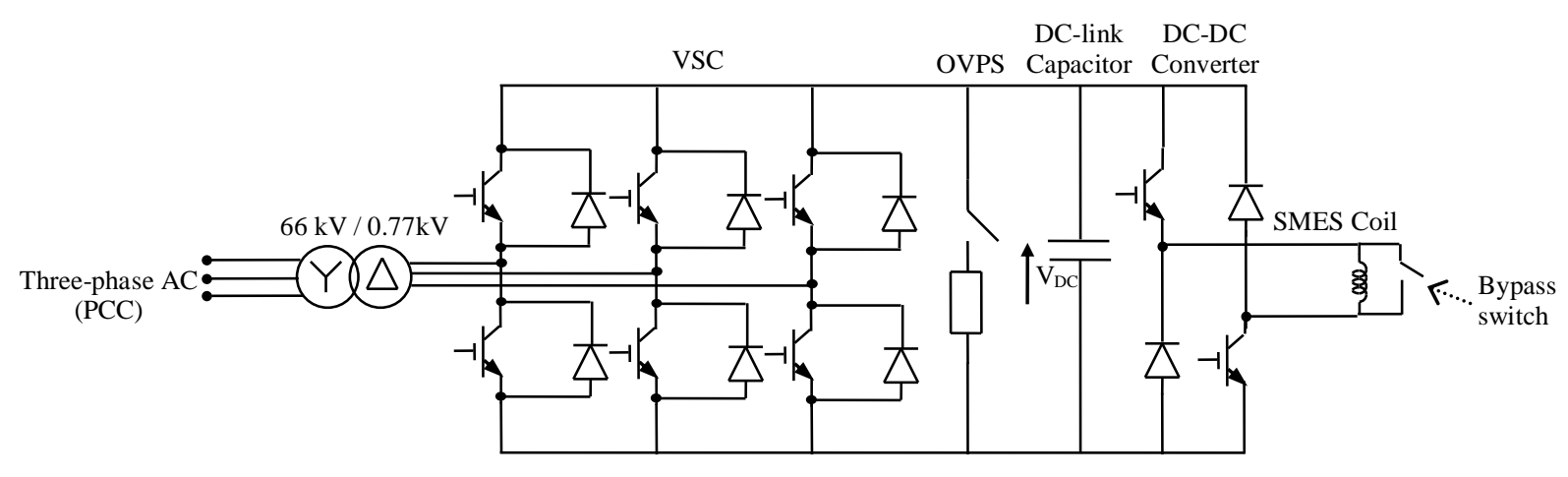

Fig. 3. SMES model.

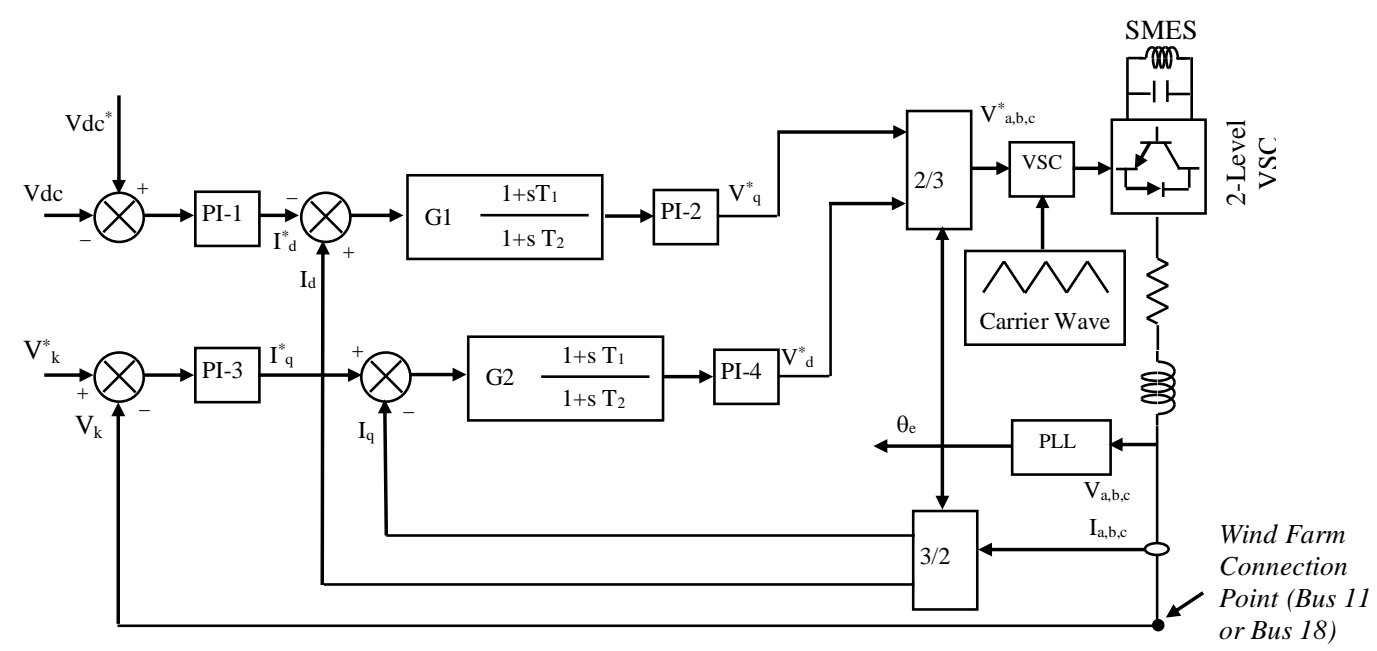

Fig. 4. Control block diagram of the VSC

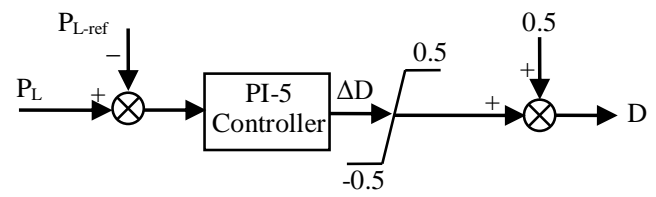


Fig. 5. Control block diagram of the DC-DC converter.

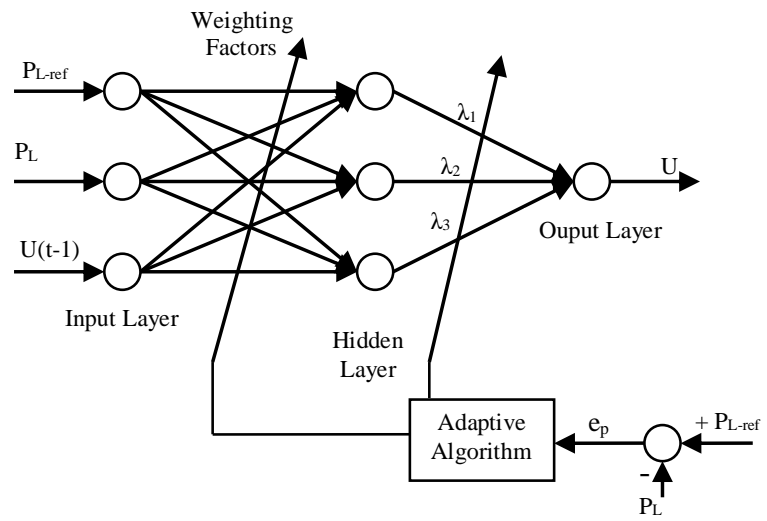

Fig. 6. Adaptive ANN structure.

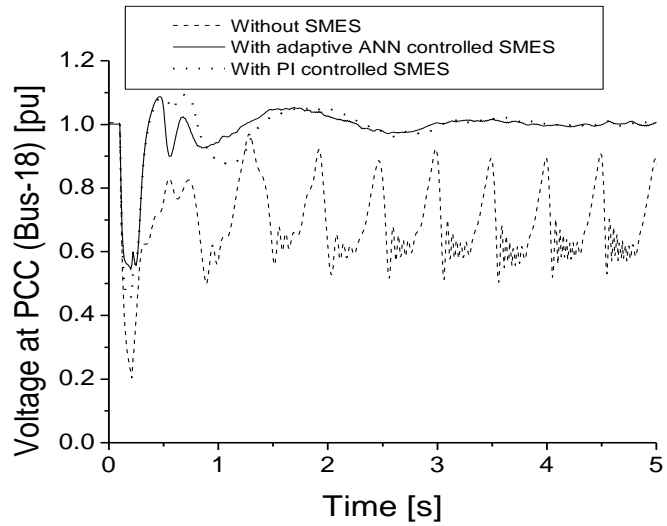

(a) 


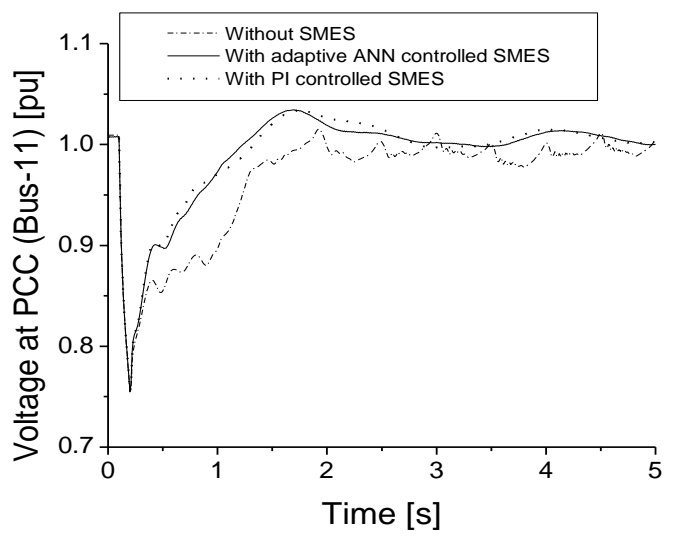

(b)

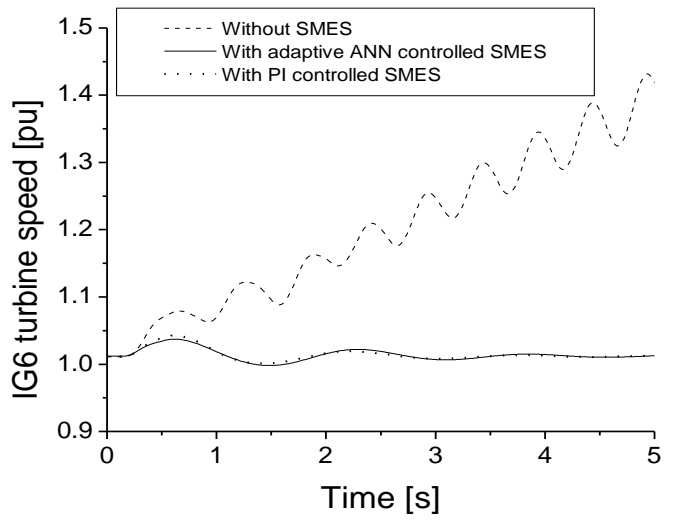

(c)

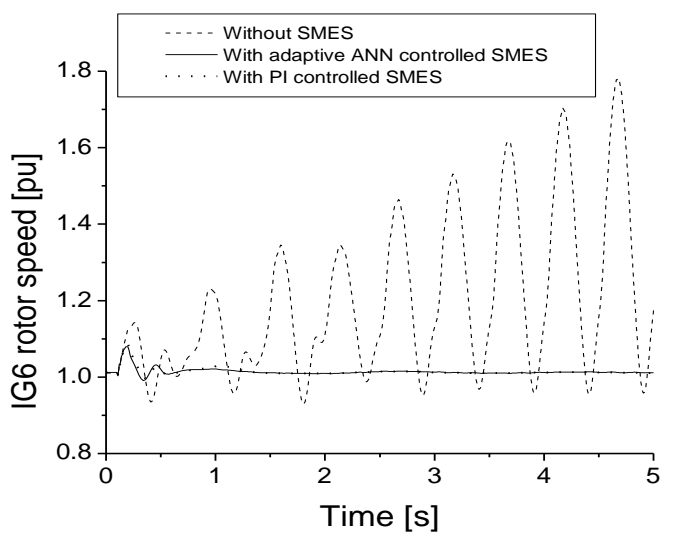

(d) 


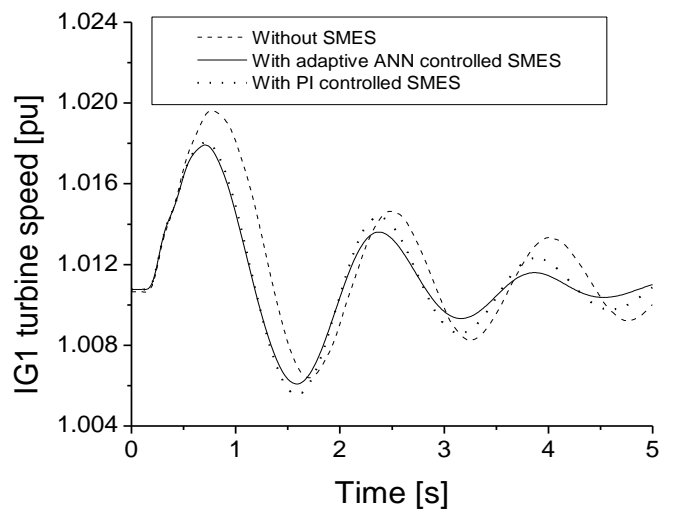

(e)

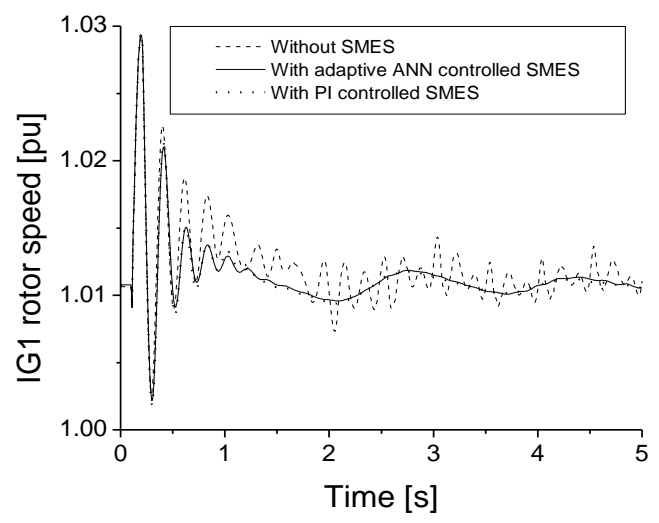

(f)

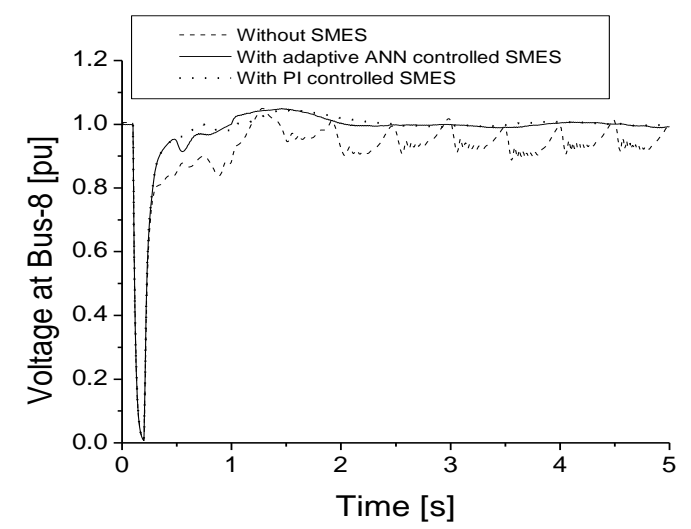

(g) 


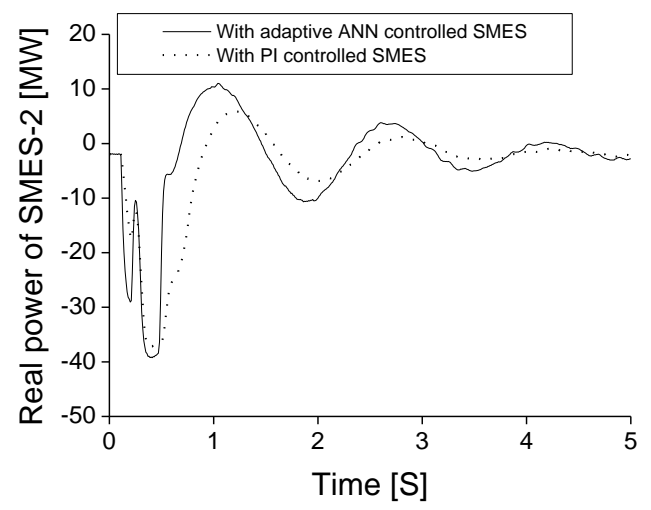

(h)

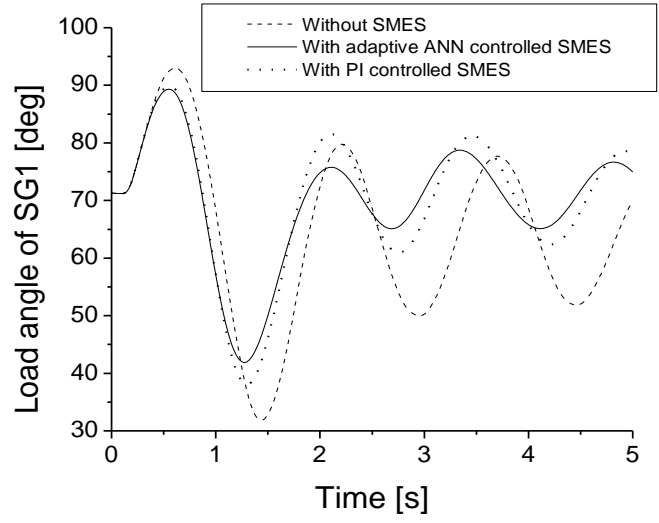

(i)

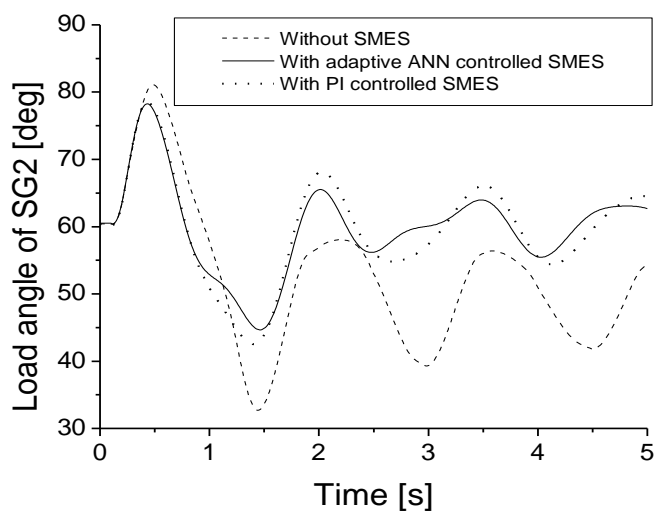

(j) 


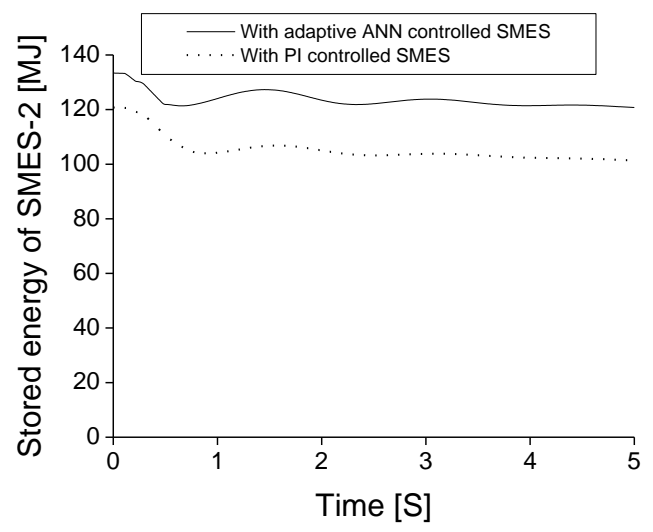

(k)

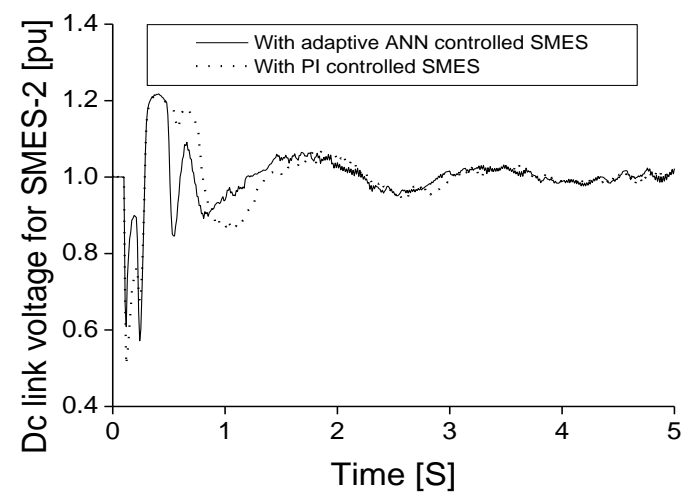

(1)

Fig. 7. Responses for $3 \mathrm{LG}$ fault (a) Voltage at PCC (bus 18) (b) Voltage at PCC (bus 11) (c) Turbine speed of WFIG-6 (d) Generator rotor speed of WFIG-6 (e) Turbine speed of WFIG-1 (f) Generator rotor speed of WFIG-1 (g) Voltage at bus-8 (h) Real power of SMES (i) Load angle of SG1 (j) Load angle of SG2 (k) Stored energy of SMES (1) DC link voltage.

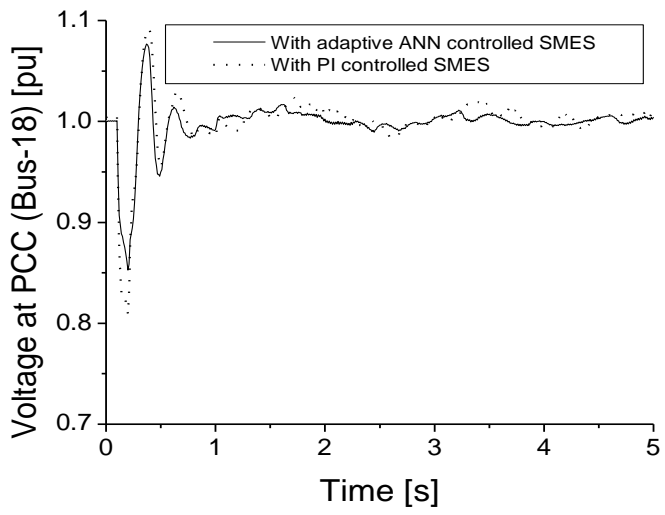

(a) 


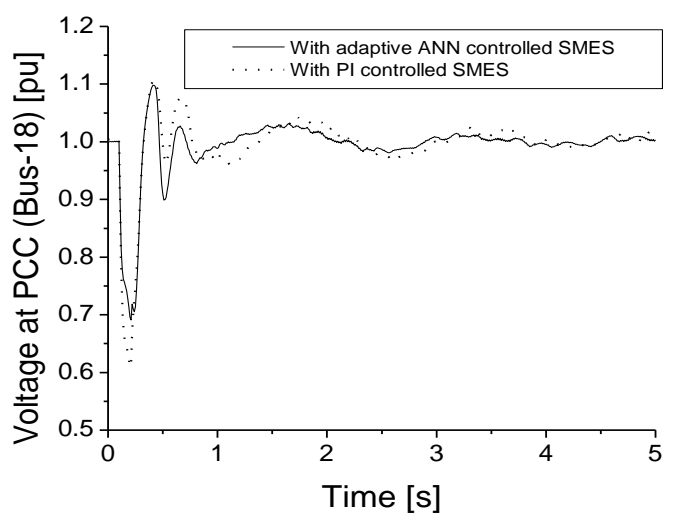

(b)

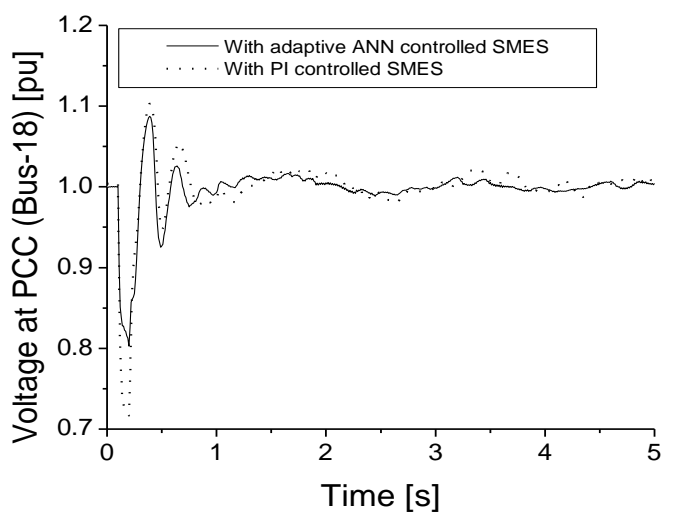

(c)

Fig. 8. Voltage response at PCC (bus 18) (a) for 1LG fault (b) for 2LG fault (c) for 2LL fault.

TABLE I

GENERATOR PARAMETERS

\begin{tabular}{|c|c|c|c|c|}
\hline & \multicolumn{2}{|c|}{ Synchronous Generators } & \multicolumn{2}{c|}{ Induction Generators } \\
\cline { 2 - 5 } & SG1 & SG2 & \multicolumn{2}{c|}{} \\
\hline MVA & 200 & 130 & MVA & 10 \\
\hline $\mathrm{r}_{\mathrm{a}}(\mathrm{pu})$ & 0.003 & 0.003 & $\mathrm{r} 1(\mathrm{pu})$ & 0.01 \\
\hline $\mathrm{X}_{\mathrm{a}}(\mathrm{pu})$ & 0.102 & 0.130 & $\mathrm{x} 1(\mathrm{pu})$ & 0.1 \\
\hline $\mathrm{X}_{\mathrm{d}}(\mathrm{pu})$ & 1.651 & 1.200 & $\mathrm{Xmu}(\mathrm{pu})$ & 3.5 \\
\hline $\mathrm{X}_{\mathrm{q}}(\mathrm{pu})$ & 1.590 & 0.700 & $\mathrm{r} 21(\mathrm{pu})$ & 0.035 \\
\hline $\mathrm{X}_{\mathrm{d}}^{\prime}(\mathrm{pu})$ & 0.232 & 0.300 & $\mathrm{x} 21(\mathrm{pu})$ & 0.030 \\
\hline $\mathrm{X}_{\mathrm{q}}^{\prime}(\mathrm{pu})$ & 0.380 & & $\mathrm{r} 22(\mathrm{pu})$ & 0.014 \\
\hline $\mathrm{X}_{\mathrm{d}}^{\prime \prime}(\mathrm{pu})$ & 0.171 & 0.220 & $\mathrm{x} 22(\mathrm{pu})$ & 0.098 \\
\hline $\mathrm{X}_{\mathrm{q}}^{\prime \prime}(\mathrm{pu})$ & 0.171 & 0.250 & $\mathrm{H}_{\mathrm{g}}(\mathrm{pu})$ & 0.3 \\
\hline
\end{tabular}




\begin{tabular}{|c|c|c|c|c|}
\hline $\mathrm{T}^{\prime} \mathrm{do}(\mathrm{s})$ & 5.900 & 5.000 & $\mathrm{H}_{\mathrm{wt}}(\mathrm{pu})$ & 3.0 \\
\hline $\mathrm{T}^{\prime} \mathrm{qo}(\mathrm{s})$ & 0.535 & & $\mathrm{~K}_{\mathrm{w}}(\mathrm{pu})$ & 90 \\
\hline $\mathrm{T}^{\prime /} \mathrm{do}(\mathrm{s})$ & 0.033 & 0.040 & & \\
\hline $\mathrm{T}^{\prime \prime} \mathrm{qo}(\mathrm{s})$ & 0.078 & 0.050 & & \\
\hline $\mathrm{H}(\mathrm{s})$ & 9.000 & 2.500 & & \\
\hline
\end{tabular}

TABLE II

DESIGN VARIABLES AND LEVELS

\begin{tabular}{|c|c|c|}
\hline $\begin{array}{c}\text { Design variables } \\
\text { Level }\end{array}$ & $X_{1}$ & $X_{2}$ \\
\hline $1(-1)$ & 0.2 & 0.05 \\
\hline $2(0)$ & 0.6 & 0.25 \\
\hline $3(1)$ & 1 & 0.5 \\
\hline
\end{tabular}

TABLE III

RANGE OF DESIGN VARIABLES AND EXPERIMENT FREQUENCY

\begin{tabular}{|c|c|c|c|c|c|}
\hline Exp. & $X_{1}$ & $X_{2}$ & $\begin{array}{c}\text { MPUS } \\
(\%)\end{array}$ & $\begin{array}{c}\text { MPOS } \\
(\%)\end{array}$ & $\begin{array}{c}\text { Ts } \\
(\mathrm{s})\end{array}$ \\
\hline 1 & 0.2 & 0.05 & 53 & 21 & 1.21 \\
\hline 2 & 1 & 0.05 & 48 & 22 & 1.26 \\
\hline 3 & 0.2 & 0.5 & 62.4 & 17 & 1.45 \\
\hline 4 & 1 & 0.5 & 51.5 & 15.6 & 1.23 \\
\hline 5 & 0.2 & 0.25 & 60.6 & 18.2 & 1.42 \\
\hline 6 & 1 & 0.25 & 49.9 & 17.8 & 1.25 \\
\hline 7 & 0.6 & 0.05 & 49.5 & 1.205 & 1.17 \\
\hline 8 & 0.6 & 0.5 & 56.6 & 1.154 & 1.38 \\
\hline 9 & 0.6 & 0.25 & 53.3 & 16.8 & 1.33 \\
\hline 10 & 0.6 & 0.25 & 53.3 & 16.8 & 1.33 \\
\hline 11 & 0.6 & 0.25 & 53.3 & 16.8 & 1.33 \\
\hline 12 & 0.6 & 0.25 & 53.3 & 16.8 & 1.33 \\
\hline 13 & 0.6 & 0.25 & 53.3 & 16.8 & 1.33 \\
\hline
\end{tabular}

TABLE IV

GA CHARACTERISTICS

\begin{tabular}{|c|c|}
\hline \multicolumn{2}{|c|}{ GA Parameters } \\
\hline Population type & Double vector \\
\hline Population size & 100 \\
\hline $\begin{array}{c}\text { Fitness scaling } \\
\text { function }\end{array}$ & Rank \\
\hline Selection function & Uniform \\
\hline Crossover fraction & 0.9 \\
\hline Crossover function & Scattered \\
\hline Migration fraction & 0.15 \\
\hline Migration interval & 20 \\
\hline
\end{tabular}


TABLE $\mathrm{V}$

OPTIMAL LEVEL AND SIZE OF DESIGN VARIABLES USING GA

\begin{tabular}{|c|c|c|}
\hline $\begin{array}{c}\text { Design variables } \\
\text { Level }\end{array}$ & $X_{1}$ & $X_{2}$ \\
\hline Optimum level & 0.04 & -0.98 \\
\hline Optimum size & 0.62 & 0.054 \\
\hline
\end{tabular}

